\title{
Cultivo de Stenachaenium megapotamicum em diferentes regimes de irrigação
}

\author{
Growing Stenachaenium megapotamicum in different irrigation regimes
}

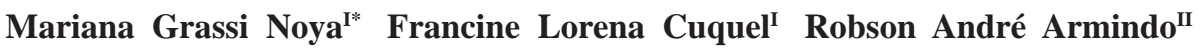 \\ Jorge Luiz Moretti de Souza ${ }^{\text {II }}$
}

RESUMO

O uso racional da água para a irrigação de jardins é uma preocupação constante em face de seu desperdício, pois pesquisas têm demonstrado que ela corresponde de 40 a $70 \%$ do consumo doméstico. Uma das estratégias empregadas para evitar este desperdício é o plantio de jardins com plantas resistentes à deficiência hídrica. Nesta pesquisa, avaliou-se o crescimento de Stenachaenium megapotamicum, uma planta subarbustiva, com potencial ornamental, nativa da Região do Sul do Brasil, que foi cultivada sob diferentes regimes de irrigação. Foram efetuados dois experimentos: a) na primavera, as plantas foram mantidas sob três turnos de rega: diário, a cada dois dias e a cada três dias; b) no outono/ inverno, as plantas foram mantidas sob quatro turnos de rega: diário, cada cinco, sete e nove dias. Os resultados obtidos demonstraram que $\boldsymbol{S}$. megapotamicum é uma planta anual de verão adequada para projetos de paisagismo, focando no uso eficiente da água.

Palavras-chave: estenaquênio, nativa, ornamental, paisagismo, economia de água, irrigação, estresse hídrico.

\section{ABSTRACT}

Water rational use for garden irrigation is a constant concern in view of it waste, because researches have shown that it corresponds to 40 to $70 \%$ of the domestic consumption. One of the strategies employed to avoid this waste is the selection and planting of drought stress resistant plants. This research aimed to evaluate the Stenachaenium megapotamicum growth, a sub shrub plant, with ornamental potential, native from South Brazil, grown under different water regimes. Two experiments were developed: a) during the spring by applying three irrigation frequencies: daily, every other day, and every three days, b) during the fall / winter by applying four irrigation frequencies: daily, five, seven and nine days. Results obtained showed that $\boldsymbol{S}$. megapotamicum is an adequate annual plant summer for landscape projects focusing in the efficient water use.

Key words: estenaquênio, native, ornamental, landscaping, water saving, irrigation, water stress.

\section{INTRODUÇÃO}

Os benefícios do paisagismo em ambientes urbanos para o bem estar humano são inquestionáveis, entretanto o uso racional da água nesses ambientes tem sido bastante discutido em face de seu desperdício na irrigação de jardins (ZOLLINGER et al., 2006; BLANUSA et al., 2010; TSIROGIANNIS, 2010; DEVITT \& MORRIS, 2010; SALVADOR et al., 2011). O uso de plantas ornamentais nativas pode ajudar na sustentabilidade dos jardins, sendo que o paisagismo sustentável, além de preservar e manter o ecossistema do local é econômico e ecológico, oferecendo baixa manutenção com reduzida necessidade de irrigação.

Embora a água utilizada para irrigar os jardins residenciais varie de acordo com fatores como o tipo da paisagem, práticas de manejo e região, pesquisas demonstram que ela corresponde de 40 a 70\% do consumo doméstico (HILAIRE et al., 2008; DEVITT \& MORRIS, 2010; KJELGREN et al., 2010). Por outro lado, a maioria das plantas utilizadas no paisagismo é pouco rústica, implicando elevada

\footnotetext{
IDepartamento de Fitotecnia, Universidade Federal do Paraná (UFPR), Rua dos Funcionários, 1540, Juvevê, 80035-050, Curitiba, PR, Brasil. E-mail: contato@marianagrassi.com.*Autor para correspondência.

IIDepartamento de Solos e Engenharia Agrícola, UFPR., Curitiba, PR. Brasil. 
demanda hídrica em períodos de seca (CHYLINSKI et al., 2007; KJELGREN et al., 2010; ROMERO, 2010; DEVITT \& MORRIS, 2010). Pesquisas têm demonstrado que as plantas nativas podem ser uma excelente alternativa para diminuir o consumo de água em jardins residenciais (TOGNON et al., 2012; SOVOCOOL et al., 2006; HILAIRE et al., 2008; REID \& OKI, 2008; SULEIMAN et al., 2011; ROMERO, 2010). Entretanto, a flora brasileira é pouco explorada para uso ornamental e menos ainda avaliada quanto ao seu potencial de uso em condições de deficiência hídrica.

Stenachaenium megapotamicum (Spreng.) Baker é uma planta da família Asteraceae com um grande potencial ornamental, subarbustiva, nativa do Sul do Brasil, de ocorrência espontânea em formações campestres e vegetação secundária. Suas inflorescências chegam até $1,80 \mathrm{~m}$ e aparecem entre os meses de março e maio, quando seus capítulos frutificam e adquirem tonalidade dourada (STUMPF et al., 2009). Sua propagação é feita por meio de sementes. Seu ciclo, em média, é de 300 dias. O objetivo no presente trabalho é avaliar o crescimento de $\boldsymbol{S}$. megapotamicum, cultivada sob diferentes regimes de irrigação.

\section{MATERIAL E MÉTODOS}

Esta pesquisa foi desenvolvida em casa de vegetação em Curitiba (PR, Brasil), clima tipo Cfb, conforme a classificação de Köppen (IAPAR, 2011). A estrutura da casa de vegetação é do tipo arco com sistema de resfriamento evaporativo do ar painel-exaustor (Pad-Fan), cobertura de polietileno transparente e fechada nas laterais com telhas onduladas de fibra de vidro translúcidas.

Mudas de $\boldsymbol{S}$. megapotamicum, obtidas por meio de sementes coletadas no município de Tapes

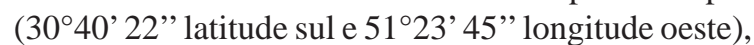
Rio Grande do Sul, em abril de 2010, com três meses de idade e $15 \mathrm{~cm}$ de altura, foram transplantadas para vasos de polietileno preto, possuindo capacidade de 5L, contendo substrato comercial próprio para plantas ornamentais a base de casca de pinus compostada e turfa vegetal, rico em matéria orgânica, e alta capacidade de retenção de água - CRA 130\% e umidade até $50 \%$, com $\mathrm{pH} 5,5$ e CE $\left(\mathrm{mS} \mathrm{cm}^{-1}\right)$ 0,6 . Foram adicionados $2,8 \mathrm{~kg}$ de substrato em cada vaso. Todos os vasos foram pesados para garantir que tivessem a mesma quantidade de substrato antes do início da pesquisa.

O primeiro experimento foi realizado na primavera, sob três turnos de rega: diário, a cada dois dias e a cada três dias. O experimento foi organizado em três blocos ao acaso, sendo que todos os blocos tiveram cada tratamento compostos por seis vasos, totalizando 54 plantas. O segundo experimento foi realizado no outono/inverno sob quatro turnos de rega: diário, cada cinco dias, cada sete dias e cada nove dias. Ele foi organizado em três blocos ao acaso, sendo que os blocos tiveram cada tratamento compostos por quatro vasos, totalizando 48 plantas.

As irrigações, nas duas etapas experimentais, foram realizadas sempre no final da tarde, utilizando-se de copo plástico graduado em milímetro. Cada vaso recebeu um volume de 300 $\mathrm{mL}$ de água, em cada uma das irrigações realizadas, sendo o volume estabelecido por meio da capacidade container do substrato. Testes realizados previamente à execução das etapas experimentais evidenciaram que vasos levados à saturação permaneciam, após a drenagem, com 300 mL de água, em média.

Em ambos os experimentos, decorridos 64 dias de pesquisa, as plantas foram avaliadas quanto a índice de sobrevivência e crescimento. A altura foi medida a partir do comprimento do colo até o ponto de inserção das folhas mais jovens. O diâmetro da planta foi medido considerando-se as extremidades de duas folhas opostas que apresentaram a maior dimensão. Todas as folhas foram contadas. A parte aérea das plantas foi seca em estufa a temperatura de $60^{\circ} \mathrm{C}$ por um período de $48 \mathrm{~h}$. As matérias fresca e seca foram medidas em balança analítica de precisão de 0,01g. A área foliar foi determinada com o auxílio do software WinRhizo, versão 4.1c para ambiente Windows, colocando-se as folhas da planta em um scanner dentro de uma bandeja de acrílico com capacidade para cinco folhas de $25 \mathrm{~cm}^{2}$ cada. Os dados diários de temperatura $\left({ }^{\circ} \mathrm{C}\right)$ no interior da casa de vegetação foram medidos e registrados com o auxílio de um termômetro instalado acima da bancada dos vasos.

Os resultados obtidos foram submetidos à análise de variância. As médias foram comparadas pelo teste de Tukey a 5\% de probabilidade.

\section{RESULTADOS E DISCUSSÃO}

\section{As plantas de $\boldsymbol{S}$. megapotamicum} obtiveram $100 \%$ de sobrevivência nos dois experimentos em todos os turnos de rega testados. A elevada sobrevivência em face à deficiência hídrica é muito favorável ao seu cultivo, visto que práticas de irrigação constantes não parecem ser necessárias para essa espécie. $\mathrm{O}$ alto grau de sobrevivência nessas condições pode estar associado a um mecanismo de adaptação das suas folhas pilosas, como o fechamento 
dos estômatos sob condições hídricas desfavoráveis (TAIZ \& ZEIGER, 2004; ZOLLINGER et al., 2006).

Nas condições dos Campos Sulinos, habitat do $S$. megapotamicum, no verão, as temperaturas máximas ficam acima de $36^{\circ} \mathrm{C}$ e, no inverno, as mínimas ficam abaixo de $0^{\circ} \mathrm{C}$ (KUINCHTNER \& BURIOL, 2001). Durante o outono, as plantas de S. megapotamicum produzem sementes e logo a seguir morrem. Na primavera, com a elevação da temperatura, suas sementes germinam e as plântulas emergem do solo, completando o ciclo ao longo do verão e início do outono. Ao longo do primeiro experimento, as temperaturas máximas diárias foram superiores a $20^{\circ} \mathrm{C}$ e as mínimas foram superiores a $9^{\circ} \mathrm{C}$, condições consideradas propícias ao crescimento das plantas de $\boldsymbol{S}$. megapotamicum (Figura 1a). No segundo experimento, as temperaturas máximas diárias foram inferiores a $25^{\circ} \mathrm{C}$ em $47 \%$ dos dias e as temperaturas mínimas foram inferiores a $10^{\circ} \mathrm{C}$ em 57\% dos dias (Figura 1b), condições térmicas que seguramente prejudicaram o crescimento e desenvolvimento das plantas no período estudado (Tabelas 1 e 2) (Figuras 2a e 2b).

No experimento desenvolvido na primavera, as plantas produzidas sob turno de rega de três dias eram mais compactas (Tabela 1). O menor crescimento de plantas sob deficiência hídrica tem sido relatado por outros autores (CARVALHO et al., 2003; PEREIRA et al., 2009). Essa é uma característica favorável no paisagismo, pois, para se obter esse efeito artificialmente, normalmente são aplicados inibidores de crescimento (CUQUEL et al., 2011).

O fato do turno de rega não ter afetado o diâmetro das plantas (Tabela 1) também é um fator positivo na composição de um jardim, pois, com

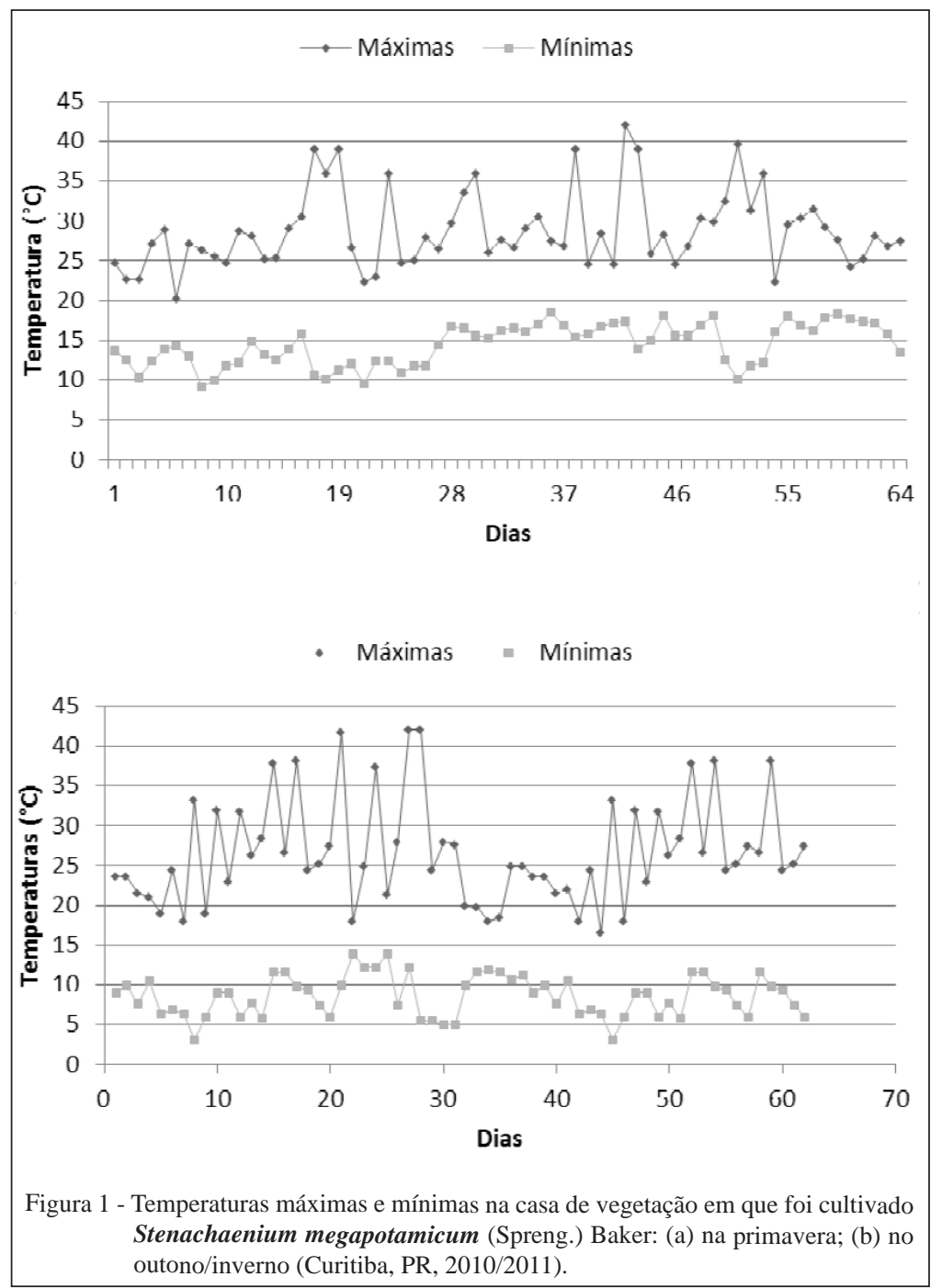

Ciência Rural, v.44, n.1, jan, 2014. 
Tabela 1 - Crescimento médio de Stenachaenium megapotamicum (Spreng.) Baker, cultivado em casa de vegetação na primavera, sob três turnos de rega, durante 64 dias, em Curitiba (PR).

\begin{tabular}{|c|c|c|c|c|c|c|}
\hline Turnos de rega & $\begin{array}{c}\text { Diâmetro da } \\
\text { planta }(\mathrm{cm})\end{array}$ & $\begin{array}{l}\text { Altura da planta } \\
(\mathrm{cm})\end{array}$ & Número folhas & $\begin{array}{c}\text { Massa da matéria } \\
\text { fresca(g) }\end{array}$ & $\begin{array}{c}\text { Massa da matéria } \\
\text { seca (g) }\end{array}$ & Área foliar $\left(\mathrm{cm}^{2}\right)$ \\
\hline Diário & $44,1 a^{*}$ & $34,3 \mathrm{a}$ & $71,7 \mathrm{a}$ & $88,4 \mathrm{a}$ & $13,1 \mathrm{a}$ & $1755,6 \mathrm{a}$ \\
\hline A cada 2 dias & $46,1 \mathrm{a}$ & $24,1 \mathrm{~b}$ & $52,7 \mathrm{~b}$ & $73,7 \mathrm{~b}$ & $10,0 \mathrm{~b}$ & 1297,4 b \\
\hline A cada 3 dias & 44,9 a & $20,1 \mathrm{c}$ & $46,9 \mathrm{~b}$ & $67,4 \mathrm{~b}$ & $9,7 \mathrm{~b}$ & $1263,5 \mathrm{~b}$ \\
\hline Média geral & 45,0 & 26,2 & 57,1 & 75,6 & 10,9 & 1438,8 \\
\hline CV (\%) & 11,9 & 17,9 & 25,4 & 20,8 & 23,5 & 19,2 \\
\hline
\end{tabular}

* Médias seguidas pela mesma letra na coluna não diferem entre si pelo teste de Tukey a 5\% de probabilidade.

plantas de maior diâmetro, é possível utilizar um espaçamento maior e, dessa forma, reduzir o número de plantas necessário para plantio e diminuir os custos. As plantas diferem na resistência ao estresse hídrico devido a diferenças morfológicas, fisiológicas e bioquímicas (TAIZ \& ZEIGER, 2004). Certamente o $S$. megapotamicum desenvolveu estes mecanismos para resistir às severas condições de seca do seu habitat (KUINCHTNER \& BURIOL, 2001).

No experimento realizado no outono/ inverno (Tabela 2 e Figura 2b), não ocorreram diferenças significativas em nenhum dos parâmetros de crescimento analisados. Os resultados permitem supor que as temperaturas baixas foram desfavoráveis ao crescimento, impedindo que fosse possível visualizar o efeito dos turnos de regas. Como a área foliar das plantas foi pequena, infere-se que a perda de água dos vasos ocorreu principalmente por evaporação, ocorrendo pouca transpiração nas plantas (TAIZ \& ZEIGER, 2004). Esse fato possibilitou, mesmo nos vasos com turno de rega de cinco, sete e nove dias, que houvesse água suficiente no substrato para permitir o crescimento das plantas. Dessa forma, a água possivelmente não foi o fator limitante para o crescimento das plantas, em todos os turnos de rega, e manteve-se um crescimento semelhante, dependendo dos períodos em que a temperatura do ar apresentou valores acima da temperatura basal de crescimento das plantas.

O consumo total de água, nas parcelas, ao longo dos 64 dias de cultivo na primavera ficou em 345,6, 118,8 e 86,4L, nos turnos de rega diário e a cada dois e três dias, respectivamente (Figura 3). Isso demonstra nitidamente a vantagem econômica e ecológica do turno de rega a cada três dias, reforçando a importância de racionalizar o consumo de água no meio urbano, podendo reduzir o consumo de água local, visto que a escassez de água é cada vez mais preocupante (SALVADOR et al., 2011). A sustentabilidade em paisagismo também foi verificada com o uso de plantas rústicas e nativas por TOGNON et al. (2012) demonstrando a possibilidade de uso com economia de água.

O consumo total de água, nas parcelas, no turno de rega ao longo dos 64 dias de cultivo no outono/inverno, ficou em 223,2, 36,0, 25,2 e 21,6L, nos turnos de rega diário e a cada cinco, sete e nove dias, respectivamente.

Os resultados obtidos evidenciam que $\boldsymbol{S}$. megapotamicum é uma planta com baixa demanda hídrica, sem a necessidade de irrigações diárias, como é o caso de muitas espécies ornamentais amplamente cultivadas, tidas como insustentáveis e extremanente exigentes em água (BLANUSA et al., 2010).

Tabela 2 - Crescimento médio de Stenachaenium megapotamicum (Spreng.) Baker, cultivado em casa de vegetação no outono/inverno, sob quatro turnos de rega, durante 64 dias, em Curitiba (PR).

\begin{tabular}{|c|c|c|c|c|c|c|}
\hline Turnos de rega & $\begin{array}{c}\text { Diâmetro da planta } \\
(\mathrm{cm})\end{array}$ & $\begin{array}{l}\text { Altura da planta } \\
(\mathrm{cm})\end{array}$ & Número folhas & $\begin{array}{c}\text { Massa da matéria } \\
\text { fresca }(\mathrm{g})\end{array}$ & $\begin{array}{c}\text { Massa da matéria } \\
\text { seca }(\mathrm{g})\end{array}$ & Área foliar $\left(\mathrm{cm}^{2}\right)$ \\
\hline Diário & $22,5 a^{*}$ & $3,5 \mathrm{a}$ & $12,5 \mathrm{a}$ & $25,1 \mathrm{a}$ & $4,2 \mathrm{a}$ & 378,9 a \\
\hline A cada 5 dias & $26,2 \mathrm{a}$ & 2,7 a & $11,6 \mathrm{a}$ & $26,1 \mathrm{a}$ & 4,3 a & $426,5 \mathrm{a}$ \\
\hline A cada 7 dias & 24,8 a & 2,1 a & $10,1 \mathrm{a}$ & $21,5 \mathrm{a}$ & 3,9 a & 370,9 a \\
\hline A cada 9 dias & $21,5 \mathrm{a}$ & 1,7 a & 9,7 a & $19,1 \mathrm{a}$ & 3,8 a & 329,6 a \\
\hline Média geral & 23,7 & 2,5 & 11 & 22,9 & 4,1 & 376,5 \\
\hline C. V. (\%) & 7,5 & 25,8 & 12,0 & 17,3 & 8,6 & 16,3 \\
\hline
\end{tabular}

* Médias seguidas pela mesma letra na coluna não diferem entre si pelo teste de Tukey a 5\% de probabilidade. 

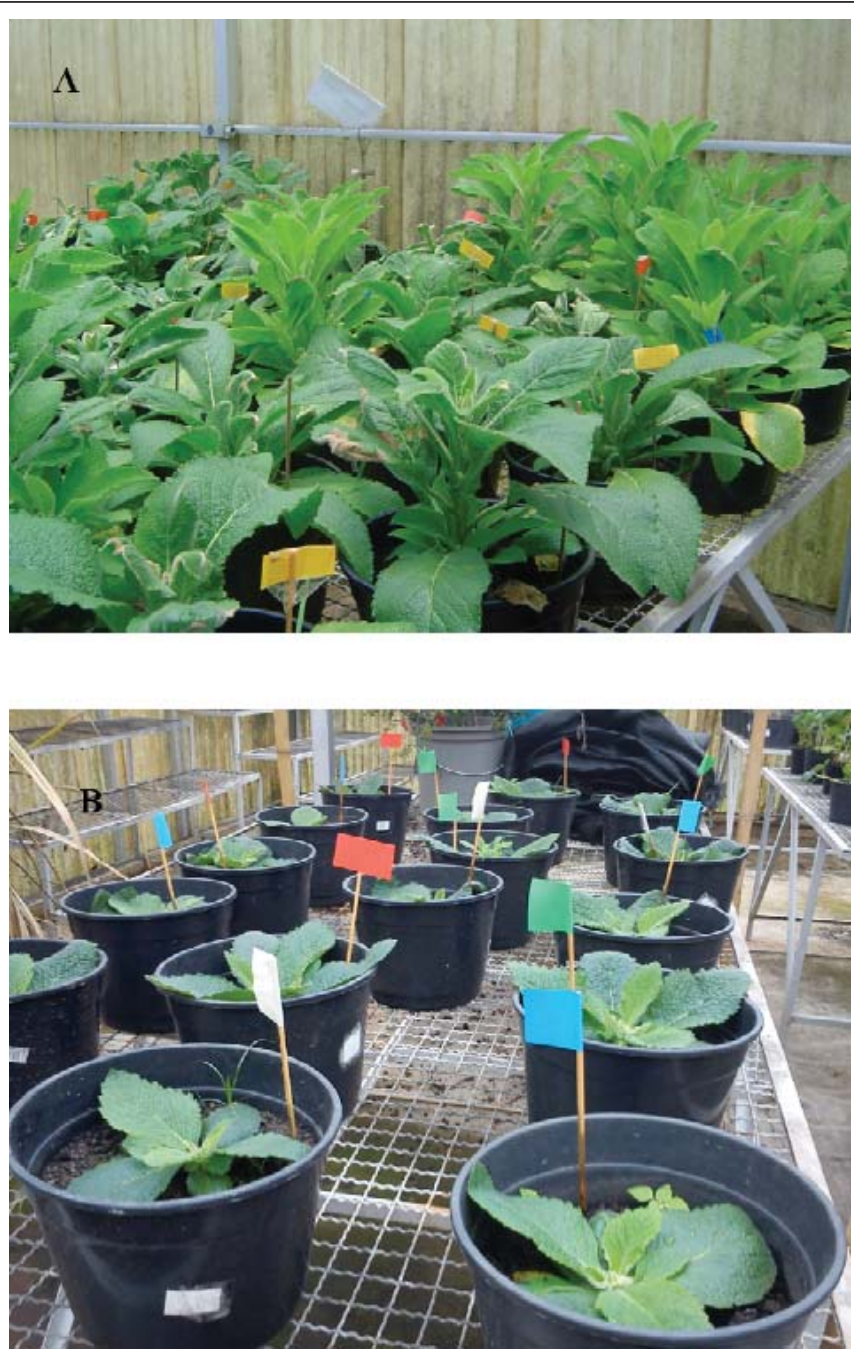

Figura 2 - Plantas de Stenachaenium megapotamicum (Spreng.) Baker, com 60 dias: (a) cultivadas na primavera; (b) cultivadas no outono/inverno (Curitiba, PR, 2010/2011).

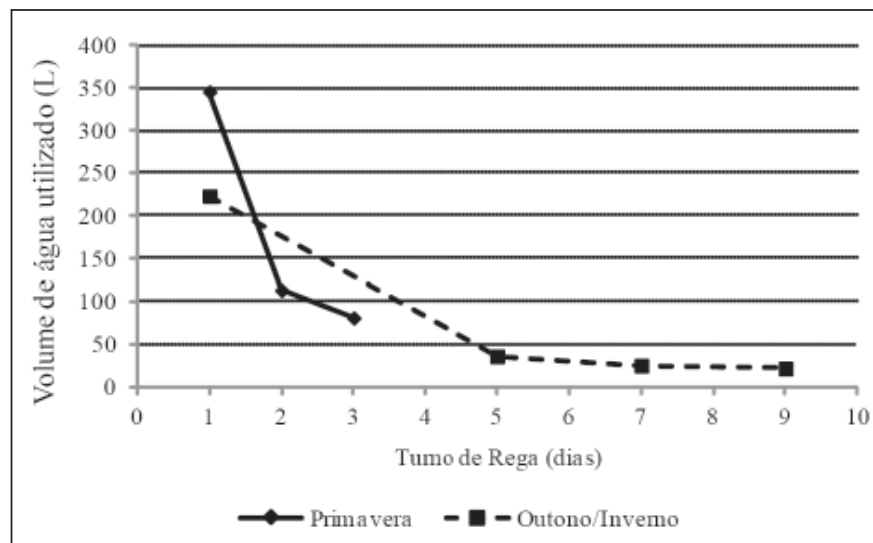

Figura 3 - Volume total de água de irrigação utilizado no cultivo de Stenachaenium megapotamicum (Spreng.) Baker, durante 64 dias nos experimentos desenvolvidos na primavera e outono/ inverno, em Curitiba, PR. 


\section{CONCLUSÃO}

S. megapotamicum é uma planta subarbustiva anual com potencial de cultivo em projetos de paisagismo sustentável no verão, devido a sua capacidade de crescimento sob condições de deficiência hídrica.

\section{REFERÊNCIAS}

BLANUSA, T. et al. Sub-irrigation of Petunia: benefits in dry summers. Acta Horticulturae, n. 881, p. 457-462, 2010. Disponível em: <http://www.actahort.org/books/881/881_73. htm>. Acesso em: 17 set. 2012.

CARVALHO, L.M. de et al. Disponibilidade de água no solo e crescimento de artemísia. Horticultura Brasileira, v.21, n.4, p.726-730, 2003. Disponível em: <http://www.scielo.br/pdf/hb/ v21n4/19448.pdf>. Acesso em: 17 set. 2012. doi: 10.1590/S010205362003000400032 .

CHYLINSKI, W.K. et al. Drought response of two bedding plants. Acta Physiologiae Plantarum, v.29, n.5, p.399406, 2007. Disponível em: <http://www.springerlink.com/ content/852n543786894x97//>. Acesso em: 17 set. 2012. doi 10.1007/s11738-007-0073-y.

CUQUEL, F.L. et al. Control of ornamental sunflower height with daminozide. Semina: Ciências Agrárias, v.31, n.1, p.1187-1192, 2011. Disponível em: <http://www.uel.br/revistas/uel/index.php/ semagrarias/article/view/2795/6919>. Acesso em: 17 set. 2012.

DEVITT, D.; MORRIS, R. Sustainable water use in urban landscapes in the $21^{\text {st }}$ century: a Las Vegas perspective. Acta Horticulturae, v.881, p.483-486, 2010. Disponível em: <http:// www.actahort.org/members/showpdf?booknrarnr=881_77>. Acesso em: 17 set. 2012.

HILAIRE S.R. et al. Efficient water use in residential urban landscapes. HortScience, v.43, n.7, p.2081-2092, 2008. Disponível em: <http://hortsci.ashspublications.org/content/43/7/2081.full.pdf>. Acesso em: 17 set. 2012.

IAPAR (INSTITUTO AGRONÔMICO DO PARANÁ). Cartas climáticas do Paraná. Disponível em: <http://www.iapar.br/ modules/conteudo/conteudo.php?conteudo=863>. Acesso em: 17 nov. 2011.

KJELGREN, R. et al. Water conservation in urban landscapes. HortScience, v.35, n.6, p.1037-1040, 2000. Disponível em: <http://hortsci.ashspublications.org/content/35/6/1037.full. pdf + html $>$. Acesso em: 17 set. 2012.

KUINCHTNER, A.; BURIOL, G.A. Clima do Estado do Rio Grande do Sul segundo a classificação de Köppen e Thornthwaite. Disciplinarum Scientia, v.2, n.1, p.171-182, 2001. Disponível em: <http://sites.unifra.br/Portals/36/tecnologicas/2001/clima.pdf>. Acesso em: 17 set. 2012

PEREIRA, J.R.D. et al. Crescimento e produção de hastes florais de gladíolo cultivado sob diferentes tensões de água no solo. Ciência e Agrotecnologia, v.33, n.4, p.965-970, 2009. Disponível em: $<$ http://www.scielo.br/scielo.php?script=sci_arttext\&pid=S1413$70542009000400004 \& \operatorname{lng}=$ en $\& n r m=i s o>$. Acesso em: 17 set. 2012. doi 10.1590/S1413-70542009000400004.

REID, S.K.; OKI, L.R. Field trials identify more native plants suited to urban landscaping. California Agriculture, v.62, n.3, p. 97-104, 2008. Disponível em: <http://escholarship.org/uc/ item/8nm499k2\#page-1>. Acesso em: 19 set. 2012.

ROMERO, C.C. Residential benchmarks for minimal landscape water use. Gainesville, FL.: Agricultural and Biological Engineering, Department University of Florida UF Water Institute, 2010. Disponível em: <http://waterinstitute.ufl.edu/news/downloads/Romero_Dukes_ Residential\%20Benchmarks_CFWC_ResearchSynthesis2010.pdf>. Acesso em: 19 set. 2012.

SALVADOR, R. et al. Irrigation performance in private urban land: a study of case in Zaragosa (Spain). Landscape and Urban Planning, v.100, n.3, p.302-311, 2011. Disponível em: <http://www.sciencedirect.com/science/journal/01692046/100/3>. Acesso em: 19 set. 2012. doi:10.1016/j.landurbplan.2010.12.018.

SOVOCOOL, K.A. et al. An in-depth investigation of xeriscape as a water conservation measure. Journal of American Water Works Association, v.98, p.82-93, 2006. Disponível em: <http://apps. awwa.org/WaterLibrary/showabstract.aspx?an=JAW_0062632>. Acesso em: 19 set. 2012.

STUMPF, E.R.T. et al. Cores e formas no bioma Pampa: plantas ornamentais nativas. Pelotas: Embrapa Clima Temperado, 2009. 276p.

SULEIMAN, M.K. et al. Performance of selected native plants under deficit irrigation. World Journal of Agricultural Science, v.7, n.1, p.19-25, 2011. Disponível em: <http://www.idosi.org/ wjas/wjas7\%281\%29/3.pdf>. Acesso em: 19 set. 2012.

TAIZ, L.; ZEIGER, E. Fisiologia vegetal. 3.ed. Porto Alegre: Artmed, 2004. 722p.

TOGNON, G.B. et al. Response to water deficit of Ipomoea cairica (L.) Sweet. Ciência e Agrotecnologia, v.36, n.3, p.318-324, 2012. Disponível em: <http://www.scielo.br/scielo. php?script=sci_arttext \&pid=S1413-70542012000300007\&lng =en \&nrm=iso>. Acesso em: 05 jul. 2013. doi:10.1590/S141370542012000300007

TSIROGIANNIS, I.L. Optimizing water use efficiency in urban landscapes using GIS. Acta Horticulturae, v.881, n.1, p.317320, 2010.

ZOLLINGER, N. et al. Drought responses of six ornamental herbaceous perennials. Scientia Horticulture, n.109, p.267274, 2006. 